\title{
O cuidado no espaço escolar: ampliando as possibilidades de cuidar
}

\section{The care at school: expanding the possibilities of caring}

\section{El cuidado en la escuela: la ampliación de las posibilidades de cuidado}

\author{
Daniela Celeste Contim dos Santos* \\ Universidade do Grande Rio - Unigranrio, Duque de Caxias, Rio de Janeiro, Brasil
}

\begin{abstract}
RESUMO
O presente artigo se destina a pensar como o cuidado pode ser performado nas práticas realizadas nos espaços escolares, partindo da orientação teórico-metodológica da Teoria Ator-rede (TAR). Percebe-se que os alunos são aqueles os quais se deve conduzir e os professores, aqueles que devem conduzi-los, muitas vezes sem saber ao certo a utilidade e a finalidade do que estão ensinando. A proposta é repensar esse espaço especialmente a partir das contribuições da obra de Annemarie Mol (2006) em seu livro A Lógica do Cuidado - Saúde e o problema da escolha do paciente. A autora propõe que o cuidado tem uma Lógica própria, intitulada por ela como Lógica do Cuidado, a qual se contrapõe à Lógica da Escolha. Ambas apresentam diferentes formas de estabelecer relações de cuidado que podem ampliar a rede do cuidar, sendo considerados todos os atores que a performam, compreendendo o processo de ensino-aprendizagem enquanto um conjunto de afetações, integrando a afetividade e a cognição.
\end{abstract}

Palavras-chave: lógica do cuidado, lógica da escolha, escola.

\begin{abstract}
This article is intended to think how care can be enacted in practices in school spaces, based on the theoretical and methodological orientation of Actor - Network Theory (ART). It is noticed that students are those which must be conducted and teachers, who shall lead them, often unsure of the usefulness and purpose of what they are teaching. The proposal is to rethink this space especially from the contributions of the work of Annemarie Mol (2006) in her book The Logic of Care - Health and the problem of patient choice. The author proposes that care has its own logic, titled for her as Logical of Care, which opposes the Logic of Choice. Both have different ways of establishing relationships of care that can extend the network of caring, all of the actors being considered that enacted it, understanding the teaching- learning as a set of affectations, integrating affection and cognition.
\end{abstract}

Keywords: logic of care, logic of choice, school. 


\begin{abstract}
RESUMEN
Este artículo tiene la intención de pensar en cómo el cuidado se puede llevar a cabo prácticas de preformas en los espacios de la escuela, basada en la orientación teórica y metodológica de la teoría del actor-red ( ART). Se dio cuenta de que los estudiantes son los que tienen que ejecutar y los maestros, que los guiará, a menudo inseguros de la utilidad y el propósito de lo que están enseñando. La propuesta es repensar este espacio, especialmente a partir de los aportes de la obra de Annemarie Mol ( 2006 ) en su libro The Logic of Care - Salud y el problema de la elección del paciente. El autor propone que la atención tiene su propia lógica, titulado por ella Cuidado tan lógico, que se opone a la lógica de la elección. Ambos tienen diferentes maneras de establecer relaciones de cuidado que pueden ampliar la red de cuidado, todos los actores que se consideró que performam, que comprende el cariño de enseñanza-aprendizaje como un conjunto de afectaciones, la integración y la cognición.
\end{abstract}

Palabras clave: cuidado de lógica, lógica de la elección, escuela.

\title{
1 I ntrodução
}

A escola é um espaço associado ao desenvolvimento e a aprendizagem, fenômenos que demandam cuidado em sua prática. A questão do cuidado nos espaços escolares se torna um objeto de estudo interessante, especialmente no momento da escolha de uma escola por pais, preocupados com a formação e/ou futuro de seus filhos.

\section{Apresentando a Lógica da escolha e a Lógica do Cuidado}

Quando pensamos em cuidado, logo nos remetemos a uma relação, a princípio, entre duas pessoas: quem cuida e quem é cuidado. Esse modelo, herdado da medicina clínica, já estabelece de antemão uma forma padronizada de cuidado: aquela em que alguém legitimado em seu saber, no caso do cuidado médico, informa a quem precisa de cuidado o que este necessita ou deve fazer para restabelecer sua condição saudável. Quando quem é cuidado segue fielmente as orientações, essa relação só tende a ser reforçada. Essa seria a forma de cuidado mais comumente praticada, definida por Mol (2006) como seguidora da Lógica da escolha, pois cabe ao paciente escolher seguir ou não as orientações recebidas. No entanto, há casos em que quem é cuidado recalcitra ${ }^{1}$. Isso pode desconcertar o cuidador e a interpretação mais comum é a de que ele não quer se cuidar ou não escolhe pelo seu bem. Nesse caso, a forma de cuidado pode ser revista. Mol (2006) analisa as formas de cuidado tradicionalmente praticadas através da Lógica da Escolha, mas também dá luz a outras formas, tão efetivas quanto ou até mais efetivas em alguns casos, como a Lógica do Cuidado. No entanto, seu trabalho é local e se 
desenvolve na área médica com pacientes diabéticos num hospital da Holanda, sendo o desafio do presente estudo pensar nas formas de cuidado performadas em outra área: a educação.

A educação é um tema amplo para começar a estudar as formas de cuidado, sendo necessário fazer um recorte para direcionar o estudo. Nesse sentido, convido você leitor a pensar na primeira escola, ou seja, aquela em que o indivíduo pode ter seu desenvolvimento mais fortemente influenciado, que é onde a criança cria a base do pensamento. Aliás, não somente a base da formação intelectual está ali, mas a escola também influencia a formação emocional, moral, cidadã do indivíduo. Portanto, muito pode estar em jogo...

Em prol do cuidado, seguindo a Lógica da Escolha, a professora diz que não pode correr para não se machucar e, quando esta se distrai, o menino corre... "Será que ele não entende que é para o próprio bem dele?" Muitas se justificariam. "Fica sentado! Calado! Agora não é hora de brincar!" O problema é que, muitas vezes, não há a discriminação entre quando se pode e quando não, ou seja, não há nenhum tipo de negociação, muito se faz mediante imposição. Não estou defendendo que não haja regras, mas hoje o pensamento que mais percorre a escola é a de um lugar de obrigação e de funcionamento, muitas vezes, mecânico, formatado. Não é raro percebermos comentários de alunos em relação à escola como um espaço chato, vivido como obrigatoriedade, onde se aprende o que não é útil e não interessa aos alunos. Ultimamente, temos percebido o que intitularei como mal-estar da educação. Os alunos não querem estar na escola, assim como seus pais e também os profissionais de educação, dentre estes, especialmente o professor. (Santos como citado em Pokladek, 2004, p. 207)

Geralmente o que se pensa, quando falamos em cuidado na escola, volta-se para o vínculo Professor-aluno. No entanto, proponho o entendimento da escola enquanto uma rede social, onde esse cuidado é estabelecido nas conexões entre os atores dessa rede. Como interferir para subverter a ideia de que é o professor quem deve dizer como o cuidado deve ser estabelecido? Para ampliar essa ideia de cuidado vertical, de cima para baixo? Há a possibilidade de um cuidado articulado também no horizontal, negociado no espaço escolar? Há a possibilidade de se pensar, assim como Mol (2006) em sua apresentação da Lógica do Cuidado, um cuidado negociado na prática, que no caso da escola, é diário?

A escola é associada no senso comum como um espaço de desenvolvimento da criança. No entanto, na prática percebemos seu foco no desenvolvimento intelectual, e este é apenas um dos aprendizados que pode ser performado nesse espaço coletivo, seja público ou particular, onde muitos atores, além de professores e alunos. 
A escola é um espaço de convívio coletivo e a ela é atribuído o lugar em que a criança aprende a se socializar. É o espaço onde a criança sai gradativamente do mundo lúdico para o mundo das responsabilidades, para o mundo do trabalho (Souza, 1995). A ideia é que, ao entrarmos na escola, pintamos, brincamos, colorimos, desenhamos e aos poucos, alguns elementos são inseridos no cotidiano: horários regulares para lanchar, almoçar, ir ao banheiro, além de provas, avaliações, etc. Há ainda outra demanda atual para a escola, a qual vem se apresentando como o principal foco desta: a preparação para o vestibular. Para alguns pais, essa questão pode ser decisiva na escolha da escola onde seu filho irá estudar. Uma escolha, que definirá sua trajetória individual enquanto profissional num mundo capitalista e individualizante, submergindo muitas vezes, a questão de sua formação enquanto ser social, enquanto cidadão.

Há, nessa escolha metodológica, uma implicação política, e não posso deixar de explicitar o que quero performar com este estudo. O que pretendo é produzir deslocamentos, traições, desvios que contribuam para pensarmos a escola enquanto espaço onde outras formas de performar o cuidado podem ser vislumbradas. O que quero fazer existir com essa escrita? Enquanto professora e psicóloga, revejo minha prática de cuidado a cada momento e é isso, leitor, que desejo despertar em quem lê esse estudo. Até mesmo quem não trabalha e nunca pensou em trabalhar com educação faz parte dessa rede, seja por ter filhos, seja por pensar na escola como espaço de esperança, tão amplamente divulgado ou, simplesmente, por ter passado por ela.

Não pensamos nesse artigo em uma educação em linha reta, que sai de um ponto e chega a outro, que sai do sensível para o inteligível, que sai da Educação Infantil ao Vestibular, mas que circula de forma a voltar-se ao humano, seguindo a perspectiva de uma Educação circular. O foco do cuidado para o ser em si e em sua relação com meio.

Segundo Melo (2011), a Teoria Ator Rede (TAR) entende a aprendizagem como um fenômeno dinâmico e multifacetado, partindo do corpo como instância mediadora que é afetado nas interações com o mundo. Nesse sentido, propõe uma reflexão sobre o ensinar, o aprender e construir conhecimento, entendendo-os como um processo vinculado e em sintonia com os outros, que leva em consideração as recalcitrâncias em humanos e não humanos, pois esta pode promover oportunidades para que novas estratégias possam ser desenvolvidas. A autora defende que a aprendizagem tem uma conotação política, na medida em que interfere na articulação do sujeito e o seu mundo. Latour (2002) defende que um aprendizado acontece quando o indivíduo se deixa afetar, o que o torna mais diferenciado por estabelecer mais conexões. 
Todo o processo de ensinar, aprender e conhecer inclui riscos, pois modifica a todos, uma vez que articula quem ensina, quem aprende e o conteúdo. Pensar num ensino vinculado envolve pensar onde ele está sendo ministrado, ou seja, na cultura onde se ambienta. Whitehead (1916) associa a educação à cultura. A escola deve se propor a formar homens que possuam tanto cultura e conhecimento especializado. A Educação se faz através da arte da utilização do conhecimento (Whitehead, 1916). Aprender ideias úteis está relacionado a manter o conhecimento vivo, não transformá-lo em algo inerte. Whitehead (1916) afirma que um professor prático sabe que a educação é um processo que exige paciência: "Todos os professores práticos sabem que a educação é um processo paciente de dominar os detalhes, minuto a minuto, hora a hora, dia a dia". ${ }^{2}$ (p. 4)

Com isso, podemos perceber que o processo de educar é um processo complexo, demandando práticas diárias de cuidado. De acordo com Law (2009), "Práticas encenam realidades incluindo realidades colaterais." 3 (p. 1) Práticas são, portanto, montagens, arranjos de relações que fazem realidades. Para isso, precisamos entender como as realidades emergem dos encontros. Se entendemos que as realidades são feitas de uma forma particular, incluímos a ideia de que poderiam ser feitas de forma diferente. Se não estamos gostando da forma como as realidades estão sendo feitas, então é importante elaborar outras práticas de métodos.

Pensando especificamente no que se refere ao cuidado na escola, muitos podem atribuir à figura do professor aquele que auxiliará esse processo, mas pela própria condição de coletividade da escola, podemos atribuir esse papel a todos os atores humanos e não humanos dessa rede: professores, família, alunos, coordenadores, diretores, merendeiras, leis, materiais, etc. Tal perspectiva amplia o pensamento sobre cuidar, pois o cuidado envolve muitos atores, e não podemos dispensá-los ao analisarmos essa rede.

Voltando então as formas de performar o cuidado, de acordo com Mol (2006), temos formas de engajamento diferentes na Lógica da escolha e na Lógica do cuidado. A autora questiona o que vem a ser um bom cuidado. Este pode não passar pelo questionamento das escolhas individuais, mas pela colaboração na tentativa de lidar com corpos doentes e vidas complexas. As vantagens e desvantagens do tratamento, muitas vezes, são negligenciadas passando a questão a focar somente na escolha do paciente. “... e finalmente há a escolha, o ato que transforma uma pessoa em um sujeito". ${ }^{4}$ (Mol, 2006, x prologue). Essa prática é por ela intitulada como Lógica da escolha, e esta seria a forma de cuidado mais comumente performada, ou seja, aquela em que os profissionais de saúde dizem ao paciente aquilo que ele precisa fazer para se recuperar ou manter-se vivo e, depende do paciente, a escolha de fazer aquilo que é indicado pelo 
especialista. Este tem, através da qualificação profissional, o lugar reconhecido de dizer o que o paciente precisa fazer. É interessante a forma como a autora mostra que a 'melhora' ou 'cura' passa geralmente pela escolha do paciente, mas há sempre a pergunta se o paciente está em condição de escolher ou, o que há por trás dessa 'escolha' do paciente que não está sendo considerada pela equipe que se propõe um cuidado do mesmo. Nesse ponto, talvez deixá-lo assumir a escolha pode configurar negligência. Mol (2006) considera essa questão ao frisar a fala de um profissional a respeito da atuação diante de um paciente psiquiátrico que não quer se levantar da cama:

Em uma enfermaria com equipe suficiente, eu pediria para uma enfermeira sentar ao lado da cama do paciente e perguntar o porquê de ele não querer se levantar. Talvez sua esposa não venha para visitá-lo essa tarde. Talvez ele se sinta mal e tema nunca ser liberado do hospital. Dê um tempo para ele, deixe-o falar. Alguém que não quer se levantar, diz o psicoterapeuta, precisa de cuidado. Oferecer a ele a escolha de ficar na cama é tanto uma forma de negligenciá-lo quanto forçá-lo a se levantar. (Mol, 2006, xi prologue) ${ }^{5}$

A autora não questiona a escolha em geral, mas sim a generalização da mesma, apresentando uma lógica diferente da lógica da escolha. A lógica do cuidado, em seu ponto de vista, contrasta com a negligência. Até que ponto aceitar a escolha do paciente pode ser considerado negligência por parte do profissional de saúde? $O$ pensamento sobre outras formas de tratamento a leva a concluir que a lógica da escolha pode conduzir a um cuidado pobre. Tudo que possa ocorrer de errado é atribuído ao risco assumido unicamente pelo paciente, sem a suposta interferência da equipe. Essa ideia de isenção do profissional no tratamento é bastante frequente. A autora defende que, em algumas situações, somos levados a fazer algo e não escolhemos fazer. Desconsiderar as condições possíveis de cuidado pode conduzir a um cuidado precário. Mol (2006) realiza um estudo sobre como esse processo ocorre com pacientes com Diabetes na Holanda. Ela afirma ser altamente específico e local seu estudo, o que não significa que sua importância seja local também. Por isso podemos aprofundar a discussão da autora e ampliar suas contribuições para outros espaços, como a escola, o que faremos mais adiante.

Ao partir desse estudo, em especial sobre a diabetes, Annemarie Mol mostrará o que entende por cuidado: “... é algo que as pessoas formatam, inventam e adaptam, uma vez e mais uma vez, na prática diária." 6 (Mol, 2006, p. 05) 0 cuidado então é feito e refeito na prática. Por isso, precisamos ver o paciente como ativo nesse processo. "Pacientes merecem ser ouvidos". ${ }^{7}$ (Mol, 2006, p.7) Até 
porque coisas inesperadas sempre acontecem e muita criatividade é envolvida em qualquer prática.

O cuidado está mais para um processo e não para um produto: "O cuidado é um processo, não tem fronteiras definidas." 8 (Mol, 2006, p. 20) No cuidado não há trocas, há um processo em que os profissionais estão oferecendo menos produtos e, os pacientes estão fazendo mais por eles mesmos. Tentar, ajustar, tentar mais uma vez. “Na Lógica do cuidado, [...], cuidado é uma interação, um processo aberto e sem fim que pode ser formatado e reformatado dependendo dos resultados". 9 (Mol, 2006, p. 23) O cuidado envolve abrir espaço para o que não é possível, ele parte não do que a pessoa quer ou sabe, mas do que ela precisa. A lógica do cuidado não explora desejos, mas o bem de alguém. Os profissionais, que encorajam seus clientes a cuidarem de si mesmos, não apelam para os seus desejos, mas para suas mentes. Cuidar de si significa adiar as complicações, no caso da diabetes; mas oferecer suporte, não significa fazer o que os pacientes querem. Nesse sentido, o cuidado não é atraente e sua base é uma constante negociação, o que pode não ser facilmente administrado numa rotina diária de um hospital e, no estudo, quando se fala no contato cotidiano de uma escola.

Na lógica do cuidado, as pessoas que precisam de cuidados não são passivas. O cuidado está encarnado, situado. (Mol, 2006) Os profissionais devem informar para então, perguntar o que eles querem. Eles poderão agir enquanto ativos, e não passivos, se houver consentimento de sua parte. O cuidado tem pouco a ver com a repreensão e mais com acalentar, alimentar, nutrir os corpos. A Lógica do Cuidado trabalha com questões práticas, procura intervir na realidade vivida pelos corpos. Nada está dado a priori. Por isso, compreender a pessoa como ativa é bem importante para se trabalhar dentro das condições de cuidado possíveis, pois são os valores desta que devem ser considerados. A pergunta que norteia a relação cuidador / cuidado não é o que deve ser feito, mas o que pode ser feito. O interessante é procurar, junto com a pessoa, o que é desejável e não somente o mais eficiente. Estar disponível para o desejável pode abrir possibilidades não esperadas e interessantes, até porque cada intervenção pode ser tratada como uma experimentação. Para promover o autocuidado, o primeiro passo é o suporte emocional. "Profissionais (...) deveriam bem informados, precisos e habilidosos." 10 (Mol, 2006, p. 63). O que interessa na lógica do cuidado são as diferenças horizontais entre as pessoas. Star (1991) tem um texto belíssimo sobre a condição de desviante em que se encontrou ao solicitar um sanduíche sem cebolas numa loja de fast-food. Em função de sua alergia a cebolas, fora do padrão de consumidor, Susan não pôde compartilhar da refeição com os amigos porque seu sanduíche demorou cerca de quarenta e cinco minutos para ficar pronto, contrariando o fast quando você requisita algo 
específico. Só é fast para quem entra no padrão. Mas todos nós não apresentamos alguma diferenciação? Tal fato levou Susan à conclusão de que esses tipos de restaurantes de comidas rápidas não estavam preparados para algo fora do ordinário. "Participar dos rituais no Mc Donald's envolve temporariamente subordinação das diferenças individuais numa coletividade social e cultural." ${ }^{11}$ (Kottak como citado em Star, 1991, p. 34). Tal fato mostra com clareza o que Law (2009) chama de American way of thinking, pois comer no referido fast-food está para além da comida, pois representa o compartilhar valores com milhares de americanos, se sentir pertencido.

Olhar as especificidades não significa que cuidados coletivos não podem ser pensados. A questão é que não devem ser pensados em termos de igualdade de indivíduos, mas como meios de promover qualidade de vida para as pessoas. Ao invés de dizer o que as pessoas precisam fazer, individualmente, as intervenções coletivas podem propor melhorar as condições coletivas em que vivemos, nos encorajando a nos cuidar. No entanto, as estatísticas é que orientam as políticas públicas.

A autora estabelece que as duas lógicas não são opostas e sim diferentes e tenta estabelecer suas diferenças: enquanto na Lógica da Escolha, o bom seria a autonomia e a igualdade e o ruim seria a opressão, na Lógica do Cuidado, o bom seria a atenção e a especificidade, o ruim seria a negligência. Na Lógica da Escolha, as pessoas são convidadas a exercitar seu próprio julgamento. Na Lógica do Cuidado, o julgamento é tirado de foco, sendo importante que as pessoas avaliem as possibilidades. Na Lógica do Cuidado, o crucial não é fazer juízos de valor, mas engajar-se em atividades práticas.

Então, na lógica do cuidado, definir 'bom', 'pior' ou 'melhor' não precede a prática, mas fazer parte dela. Uma parte difícil também. Alguém que abra espaço para ambivalências, desacordos, inseguranças, incompreensões e conflitos. Ninguém disse que o cuidado seria fácil. ${ }^{12}$ (Mol, 2006, p. 87)

O que é valorizado na Lógica do Cuidado é a consulta e não o debate. Um lugar de conversa, de troca de experiência, conhecimento, sugestões, palavras de conforto, olhares, toques, apertos de mão. "Boa comunicação é uma precondição crucial para um bom cuidado. [...] I sso melhora a vida diária das pessoas". ${ }^{13}$ (Mol, 2006, p. 88) A Lógica do Cuidado prioriza a narrativa e a Lógica da Escolha, a argumentação. Nesta, o julgamento precede a ação. Na Lógica do Cuidado, o que é bom, o que torna a vida melhor, não é dado antes do ato e sim, estabelecido durante o caminho. Tal imprevisibilidade pode apresentar dificuldades. 
Você dá o seu melhor, mas é impossível predizer como uma tentativa de fazer bom irá funcionar na prática. [...] Na lógica do cuidado incerteza é crônica, e argumentos adicionais não podem esperar alterar isso. Você faz o que pode, você tenta e tenta novamente. ${ }^{14}$ (Mol, 2006, p. 90)

O profissional do cuidado precisa estar pronto para lidar com o que aparece, ou seja, com os problemas que emergem. Não há segurança, nem satisfação pessoal, mas há algo de positivo: há responsabilidade distribuída. $\mathrm{Na}$ Lógica da Escolha, todas as consequências devem ser aceitas como provenientes da escolha, porque escolher implica que alguém é responsável pelo que aconteceu. Na Lógica do Cuidado, isso é diferente: coisas inesperadas sempre podem ocorrer. Precisamos encarar o que acontece de errado com a compreensão de que não é sua falha ou de outros. Isso significa que mesmo agindo da forma esperada, considerada boa, podemos encarar um resultado ruim. É importante então focar no presente para pensar no que precisa ser feito e não desistir. A lógica do cuidado não impõe culpa, mas chama por perseverança.

$\mathrm{Na}$ lógica da escolha, o ator é aquele que escolhe, mas na lógica do cuidado, os atores fazem coisas e não precisam estar sozinhos. “... na lógica do cuidado a ação movimenta. Um momento você é cuidado e, no momento seguinte, é de você que cuidam. Tarefas de cuidado são divididas de formas diferentes. Elas também mudam." ${ }^{15}$ (Mol, 2006, p. 92)

Mol (2006) reforça que não está defendendo que a Lógica do Cuidado é melhor que a Lógica da Escolha; mas, em sua opinião, aquela é melhor para orientar na vivência do imprevisível. Isso só é possível porque a Lógica do Cuidado não é sólida, e sim fluida e adaptável. A Lógica do Cuidado não é melhor que a Lógica da Escolha. Esta apenas recruta e engaja atores de modo diferente.

A Lógica do Cuidado requer profissionais atentos aos efeitos, atentos às experiências e especialmente interessados em pesquisar, em aprender com os casos, não para repeti-los como parâmetros, mas para despertar a nossa sensibilidade, para incorporar todos os atores. E para tal, precisamos de espaços, que segundo Mol (2006), seriam espaços experimentais para que possamos aprender não somente com os acertos, mas com os erros, com as falhas também. Isso é fundamental para a lógica do cuidado: tornar o profissional um constante experimentador de seu próprio trabalho.

\section{As duas Lógicas no espaço escolar}

Você deve estar se perguntando o que isso tudo tem a ver com a escola? A escolha de uma escola para seu filho leva alguns pais a 
pensar sobre que tipo de cuidado eles gostariam que seu filho recebesse ou que tipo de formação eles receberão. Estudar de forma aprofundada as práticas de cuidado nos espaços escolares, pode nos ensinar acerca de nossa sensibilidade para com o cuidar na escola, repensando as práticas de cuidado tradicionalmente vistas em escolas, onde geralmente o professor ou funcionários da escola dizem o que se deve fazer.

Meu desafio, então, é partir dessa perspectiva de compreensão de cuidado para pensarmos a escola. Para tanto, inicialmente buscarei trazer os questionamentos que Mol (2006) desenvolve no hospital para o âmbito escolar. Ficará evidente leitor, que algumas afirmações feitas são fruto de minha experiência há sete anos como professora da rede pública e há cinco da rede particular de ensino.

Assim como o médico, o professor tem seu lugar legitimado pelo saber científico. No entanto, ao longo dos últimos quarenta anos, essa profissão passou por uma mudança considerável em seu status social. Essa mudança de status traz uma modificação na forma como os professores são percebidos. Há algum tempo atrás, ao professor era atribuído um lugar de admiração e respeito, hoje em dia, é comum ouvirmos professores relatando o desrespeito não só de alunos, mas de responsáveis e até de colegas que dividem o espaço escolar. Como se, antes, a Lógica da escolha funcionasse bem. $O$ professor determinava o que era para ser feito e cabia ao aluno (pais, comunidade) acatar sua determinação. Pode até soar como um saudosismo (confesso que, em certos momentos, é bem confortável essa posição e a Lógica da escolha é pertinente em muitas situações), mas tal prática também não incluía a voz do aluno e a de outros atores. Depois de várias produções que incentivavam a importância de incluir o aluno no processo, o que nos parece agora é a inversão da Lógica da escolha. O aluno (muitas vezes apoiado fortemente por seus pais) hoje é quem questiona a correção e condutas dos professores. Minha audácia está em apontar, leitor, que talvez uma boa ideia fosse a avaliação dos casos em que caberia a Lógica da escolha e quando caberia a Lógica do cuidado e não a simples inversão de papéis de quem é passivo na Lógica da escolha. Se antes, o aluno era passivo em relação à decisão do professor, hoje ele é ativo em algumas circunstâncias, sendo o professor passivo. $O$ professor precisa estar atento às especificidades do aluno e este precisa responder ao processo de seu desenvolvimento. A educação não está na mão de um ou de outro, mas na de ambas em constante negociação.

Costumo ouvir em salas de professores, centros de estudos, conselhos de classe, reuniões de colegiados, queixas voltadas à procura de um culpado para a atual circunstância, na qual se encontra a escola. Uma das características da Lógica da escolha é a procura de um culpado, o que em algumas situações substitui o 
engajamento, levando a situação de negligência. Para Mol (2006), a Lógica do cuidado contrasta com a negligência. O processo do cuidado é entendido enquanto um projeto de parcerias, e não um processo de abandonos. Talvez hoje, os serviços de Educação e Saúde no Brasil sejam os menos qualificados pela adoção em ambos da Lógica da escolha que viabiliza a negligência e o pouco engajamento, sem avaliar as situações nas quais cabe discernir entre as duas lógicas. Por isso, faz-se necessário, pela política engajada nesta escrita, ampliar a proposta de Mol em meu estudo, saindo da área de saúde. Com isso, me desafiando e desafiando a você, leitor, a pensar numa nova lógica, até porque se você já passou pela escola e pretende ter filhos, um dia escolherá uma escola para eles. Se você não pretende ter filhos, não pense que está isento de pensar a escola, pois certamente serão elas a formar os futuros vereadores, senadores, deputados, governadores, prefeitos e presidentes, cujas influências afetarão sua vida em algum nível.

Mas de quem deveria ser a reflexão da educação? Não seria do educador refletir sobre sua prática? Não caberia ao educando refletir sobre a educação que recebe? Não deve cada indivíduo refletir sobre a educação que a sociedade produz? (Gallo, 2008, p. 55)

A educação, portanto, é um assunto que merece cuidado e a escola precisa ser pensada como um espaço em que alguns cuidados se desenvolvem. Um cuidado precário, de acordo com Mol (2006), negligencia as condições de cuidado possíveis. Todos os atores envolvidos nesse processo precisam ser ouvidos, não só professores e alunos, mas pais, inspetores, secretárias, merendeiras, comunidade, sociedade. Olhando sob essa perspectiva, estamos todos negligentes em relação ao mundo em que queremos viver. Estar aberto às condições de cuidado possíveis tem a ver, de acordo com a Lógica do cuidado, estar aberto ao inesperado, pois é este que desenvolverá a criatividade para encontrarmos a melhor maneira de nos ajustarmos. Seguir a Lógica da escolha é oferecer um padrão, formatar a forma de aprender e ensinar, esperando que o sujeito se adapte, ou melhor, escolha se adaptar à escola. Podemos pensar hoje o quanto o padrão está em passar no vestibular. O geral do momento em que visa a atender a todos, não atende a ninguém, pois passa pelo superficial, justamente para atender a todos, não aprofundando, ou seja, não especificando, não singularizando. Quando temos um padrão para encaixar, o desvio costuma ser punido, mas a Lógica do cuidado tem pouco a ver com a repreensão e mais com acalentar, alimentar, nutrir, preencher, utilizando as palavras da autora como citado anteriormente. 
Estar aberto ao imprevisível é desconfortável, pois exige um estado de atenção constante. Assim como num consultório, na sala de aula, ou melhor, na escola, nada está dado. Assim como os profissionais de saúde, aos profissionais da educação é necessário conhecimento, precisão e habilidade. Algum indivíduo deveria ser obrigado a autorrealizar-se, a desenvolver-se? Isso poderia fazer parte de seu processo natural, assim como uma planta que cresce em busca do sol, uma criança poderia ser incentivada a desenvolver-se no que mais a atende. Nesse sentido, o currículo escolar pode ser uma prisão para aqueles que não atendem às expectativas do que a escola quer formar para o mundo atual. Por isso, a pergunta pode ser mais profunda no que diz respeito a quem estamos formando através das práticas de cuidado atual?

Outro questionamento bem interessante de transportarmos do hospital para a escola é quanto a priorizar a singularidade ou a igualdade. A Lógica da Escolha privilegia a igualdade e podemos perceber isso na uniformização dos alunos. Não que eu defenda a ideia de que não deve haver uniformes, mas a concepção implícita neles é padronização, excluindo a diferença. Pensar em padrão é pensar que todos são iguais. Avaliar todos com a mesma prova, por exemplo, pode anular a influência de algumas interferências como local da escola, profissionais, tamanho, etc. Nessa mesma linha, encontramos as políticas públicas, as quais são orientadas pelas estatísticas de normalidade e não pela questão da qualidade de vida (Mol, 2006) e, no nosso caso, na qualidade de ensino.

Um bom cuidado não parte de apelos gerais, mas depende de especificações. A Lógica do cuidado, por sua vez, privilegia a diversidade, as quais podem ser mais ricas, uma vez que possibilitam diferentes formas de experiência, de vivência. Não se busca aqui abolir a condição de desviante do padrão, mas lidar com ele, pois retomando Star (1991), em algum nível, cedo ou tarde, todos nós nos encontraremos na condição de desviantes.

Comparando a Lógica da escolha com a Lógica do cuidado, podemos estabelecer algumas diferenças, as quais podemos perceber em escolas de uma forma geral. Volto a dizer que a coexistência de ambas as lógicas pode promover uma nova forma de cuidar, avaliando cada situação:

\begin{tabular}{|l|l|}
\hline \multicolumn{1}{|c|}{ Lógica do Cuidado } & \multicolumn{1}{c|}{ Lógica da Escolha } \\
\hline Atenção às especificidades & Uniformidade \\
\hline Avaliar possibilidades & Julgamento \\
\hline Cidadãos governam juntos & $\begin{array}{l}\text { Consumidores escolhem } \\
\text { individualmente }\end{array}$ \\
\hline Engajamento & Escolha \\
\hline Diálogo & Debate \\
\hline
\end{tabular}




\begin{tabular}{|l|l|}
\hline Narrativa & Argumentação \\
\hline Ação Moral / Perseverança & Acomodação \\
\hline Negociação / Confronto & Responsabilização individual \\
\hline Companheirismo & Solidão \\
\hline Qualidade & Quantidade \\
\hline
\end{tabular}

Assim como no hospital, a Lógica do cuidado pode ser uma alternativa viável à Lógica da escolha ou uma companheira da mesma na escola, pois pode ser mais interessante para lidar com imprevisibilidade.

Por fim, não podemos deixar de analisar como os currículos escolares expõem a dicotomia mente $x$ corpo na distribuição de tempo de suas disciplinas. Certa vez, quando interrogada por um aluno sobre o porquê de ele precisar estudar Matemática se queria fazer História, me percebi dando a seguinte resposta: 'No Ensino Fundamental e Médio, você precisa conhecer um pouco de tudo para poder entender o mínimo do que o rodeia, e também para experimentar outros conhecimentos até precisar defini-los antes de entrar na faculdade'. Aí ele me respondeu: 'Então deveriam ser dois tempos de Matemática e não quatro, pois só tem dois de História.' Sua resposta me fez pensar em como os currículos privilegiam a Mente em detrimento do Corpo. No entanto, pensarmos numa mudança curricular é algo ainda ambicioso, até porque essa se efetiva pelas práticas cotidianas numa escola. Por isso, pensar a Lógica do cuidado na escola nos desloca para pensarmos formas diferentes de performarmos as práticas de cuidado diárias. Talvez a dificuldade seja o que essa Lógica exige daqueles que se envolvem na escola (profissionais, pais, alunos, comunidade, sociedade): atenção aos resultados das tentativas, atenção à experiência e interesse em pesquisar. Aprender com erros além dos acertos e, especificamente, esperar dos atores envolvidos no processo que estejam atentos aos trabalhos desenvolvidos. 0 cuidado pode demandar considerações mais específicas, talvez um pouco mais singulares, levantando o caso da peculiaridade do encontro em que ambos, cuidador e cuidado, podem estar em negociação.

\section{Conclusão}

Em muitos momentos da leitura deste artigo, você pode ter a sensação de uma hierarquia da Lógica do cuidado sobre a Lógica da escolha. Talvez a impressão possa ser inclusive pela nomenclatura usada. Como a Lógica da escolha é mais frequentemente observada nas práticas atuais de cuidado, está consequentemente mais passível a críticas. Nesse sentido, a ideia não é o de hierarquizar, mas ampliar 
possibilidades. Pela pouca observação de práticas de cuidar que seguem a Lógica do cuidado, talvez haja a impressão de que esta seria ideal, por ser algo recente, novo, pouco falado. No entanto, talvez a pouca aparição desta, nos faz também ver menos suas fraquezas, pois quando algo é amplamente divulgado e estabelecido, mais recorrente é a identificação de suas fragilidades. Talvez tenhamos poucas experiências de práticas de cuidar que seguem a Lógica do cuidado para que seus pontos fracos possam ser considerados.

O fato é que a Lógica do cuidado amplia a possibilidade de performar o cuidar, que envolve vínculo, afetação, negociação. Percebo, em minha experiência, a grande repercussão de formas de cuidado a partir da Lógica da escolha na escola. Questões como alunos indisciplinados colocados fora da sala, professores que oferecem pouco em função da desvalorização social e financeira, procura de um culpado: família, professores, escola, governo, desinteresse... Talvez seja possível pensar numa escola com atenção às singularidades, com avaliação das possibilidades, engajamento, perseverança, paciência, negociação, qualidade do contato, vínculo. Tais características performam um cuidado não como algo pronto a ser determinado, dado e seguido, mas pela compreensão do cuidado como processo, que ocorre de forma devagar, com esforço, dedicação, planejamento. Não sugiro que abandonemos a Lógica da escolha, mas que inauguremos um outro campo de cuidado em educação. Um outro devir escola que possa somar, modificar, articular as formas já estabelecidas de cuidado para que outras possam ser pensadas.

\section{Referências}

Gallo, S. (2008). Deleuze \& a Educação. 2a Ed., Belo Horizonte: Autêntica.

Latour, B. (2002) How to talk about the body? Recuperado em 13 de fevereiro, 2013, de http://www. ensmp.fr

Melo, M.(2011) Discutindo a aprendizagem sob a perspectiva da teoria ator-rede. Educar em Revista, (39), 177-190.

Mol, A. (2006) The logic of care - Health and the problem of patient choice. New York: Routledge.

Santos, D. (2004). Relato de uma ação psicopedagógica: construindo caminhos para uma prática inclusiva. In: D. Pokladek (Orgs.) A fenomenologia do cuidar: prática dos horizontes vividos nas áreas da saúde, educacional e organizacional. (pp.205- 220). São Paulo: Vetor.

Souza, S (1995). Um outro olhar: Filosofia. São Paulo: FTD. 
Star, S.(1991). Power, technology and the phenomenology of conventions: on being allergic to onions. In: J. Law (Org.) A Sociology of Monsters: Essays on Power, Technology and Domination. Recuperado em 25 de julho, 2012, de http: //archivocienciassociales. files. wordpress.com/2012/09/joh n_law_a_sociology_of_monsters_essays_on_power_technology and_domination 1991.pdf

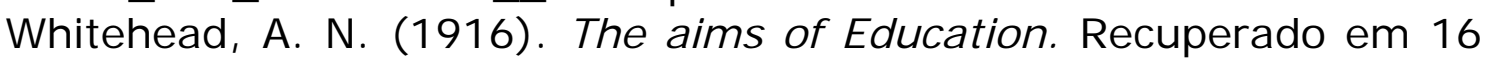
de janeiro, 2013, de

http://www.anthonyflood.com/whiteheadeducation.htm

\section{Endereço para correspondência \\ Daniela Celeste Contim dos Santos}

Universidade do Grande Rio - Unigranrio

Rua Professor José de Souza Herdy, 1160, 25 de Agosto, Duque de Caxias - RJ, Brasil

Endereço eletrônico: danielacontim@yahoo.com.br

Recebido em: 08/06/2014

Reformulado em: 09/09/2014

Aceito para publicação em: 11/09/2014

\section{Notas}

* Possui graduação e licenciatura em Psicologia pela Universidade Federal do Rio de Janeiro (2006) e licenciatura plena em Língua Inglesa pela Universidade Castelo Branco (2005). Especialista em Psicologia Clínica na Abordagem da Gestalt-terapia pelo Instituto Carioca de Gestalt-terapia (2008) e mestre em Psicologia Social pela Uerj(2013). Atualmente é psicóloga clínica, coordenadora do curso de Psicopedagogia Clínica e Institucional da Unigranrio, professora docente I da Secretaria Estadual de Educação e da Secretaria Municipal de Educação.Tem experiência como psicóloga júnior na área de Recursos Humanos, como professora do ensino fundamental, médio e superior e também como psicóloga clínica em atendimentos individuais, de casal e de família.

1 "Recalcitrar: "do latim recalcitrare, verbo intransitivo. Resistir, desobedecendo; não ceder; teimar, escoicear, desobedecer" (Tsallis, A. Entre terapeutas e palhaços: A recalcitrância em ação. 2005, p. 22) tese de doutorado, Universidade do estado do Rio de Janeiro, Rio de Janeiro, RJ, Brasil.

2 "All practical teachers know that education is a patient process of mastering of details, minute by minute, hour by hour, day by day." (tradução nossa)

3 "Practices enact realities including collateral realities." (tradução nossa)

4 "... and finally there is 'choice', the very act that turns a person into a subject." (tradução nossa)

${ }^{5}$ On a ward with enough staff, I'd send a nurse to sit next to the patient's bed and ask why he does not want to get up. Maybe his wife is not coming for a visit that afternoon. Maybe he feels awful and fears he will never be released from hospital. Take time for him, let him talk'. Someone who does not want to get up, says the psychotherapist, needs care. Offering him the choice of staying in bed is as much a way of neglecting him as is forcing him to get up. (tradução nossa)

6 “... it is something that people shape, invent and adapt, time and again, in everyday practice." (tradução nossa)

7 "Patients deserve to be heard." (tradução nossa)

8 "Care is a process: it does not have clear boundaries." (tradução nossa) 
9 "In the logic of care, $[\ldots]$, care is an interactive, open-ended process that may be shaped and reshaped depending on its results." (tradução nossa)

10 "Professionals should provide good information, and properly implement the interventions for which their patients opt. They should be knowledgeable, accurate and skilful." (tradução nossa)

11 "Participation on McDonald's rituals involves temporary subordination of individual differences in a social and cultural collectivity." (tradução nossa)

12 "So in the logic of care, defining 'good', 'worse' and 'better' does not precede practice, but forms part of it. A difficult part too. One that gives ample occasion for ambivalences, disagreements, insecurities, misunderstandings and conflicts. Nobody ever said that care is would be easy". (tradução nossa)

13 "Good communication is a crucial precondition for good care. [...] It improves people's daily lives." (tradução nossa)

14 "You do your best, but it is impossible to predict how an attempt to do good will work out in practice. [...] In the logic of care uncertainty is chronic, and additional arguments cannot hope to alter this. You do what you can, you try and try again." (tradução nossa)

15 “... in the logic of care the action moves around. One moment you care and the next you are taken care of. Care tasks are shared in varying ways. They also change." (tradução nossa) 